\title{
Characterization of Silicon Crystals Grown from Melt in a Granulate Crucible
}

\author{
K. DADZIS ${ }^{10},{ }^{1,5}$ R. MENZEL, ${ }^{1}$ U. JUDA,${ }^{1}$ K. IRMSCHER,${ }^{1}$ C. KRANERT,${ }^{2,4}$ \\ M. MÜLLER ${ }^{3}$ M. EHRL, ${ }^{3}$ R. WEINGÄRTNER, ${ }^{4}$ C. REIMANN, ${ }^{2,4}$ \\ N. ABROSIMOV, ${ }^{1}$ and H. RIEMANN ${ }^{1}$ \\ 1.-Leibniz-Institut für Kristallzüchtung (IKZ), Berlin, Germany. 2.-Fraunhofer THM, \\ Freiberg, Germany. 3.-Institute of Applied Physics, TU Freiberg, Germany. 4.-Fraunhofer \\ IISB, Erlangen, Germany. 5.—e-mail: kaspars.dadzis@ikz-berlin.de
}

The growth of silicon crystals from a melt contained in a granulate crucible significantly differs from the classical growth techniques because of the granulate feedstock and the continuous growth process. We performed a systematic study of impurities and structural defects in several such crystals with diameters up to $60 \mathrm{~mm}$. The possible origin of various defects is discussed and attributed to feedstock (concentration of transition metals), growth setup (carbon concentration), or growth process (dislocation density), showing the potential for further optimization. A distinct correlation between crystal defects and bulk carrier lifetime is observed. A bulk carrier lifetime with values up to $600 \mu \mathrm{s}$ on passivated surfaces of dislocation-free parts of the crystal is currently achieved.

Key words: Crystal growth, silicon, defect characterization, carrier lifetime

\section{INTRODUCTION}

Crystalline silicon for applications in semiconductor electronics and photovoltaics is produced by several methods including Czochralski (CZ), floating zone (FZ) and directional solidification (DS), which are selected based on a sensitive balance between crystal quality and production cost targets. ${ }^{1}$ The growth of silicon crystals from a silicon granulate crucible (Si-GC) is a new method being actively developed at the Leibniz Institute for Crystal Growth (IKZ). The Si-GC method has the potential to further push the present quality and cost limits. ${ }^{2,3}$ It offers continuous growth from a melt without any contact to a foreign material, as well as a clean thermal environment based on induction heating. Thus, the Si-GC method avoids melt contamination from crucible, heaters, and

(Received March 6, 2020; accepted June 30, 2020;

published online July 24, 2020) other parts of a complex hot-zone design known in $\mathrm{CZ}$ growth; it eliminates the need for special feed rods and the limits for crystal diameter known in FZ growth. To date, Si-GC crystals with diameters up to $100 \mathrm{~mm}$ have been demonstrated.

The Si-GC process differs from the $\mathrm{CZ}$ and $\mathrm{FZ}$ techniques both in growth conditions such as thermal gradients in the crystal, and in the typical concentrations of impurities in the crystal. This leads to new defect types and new patterns of defect distribution over large crystal volumes compared to previous studies in the literature, see, e.g., Ref. 4 for a review. The present study is devoted to the analysis of defect structures in Si-GC crystals using a large variety of spectroscopic, topographic, and other experimental methods. Special attention is given to defect mapping over large sample areas. These results give new insights into the relations between feedstock material, crystal growth conditions, defect structures, and application-relevant quality parameters for silicon. This is a key aspect 
for developing efficient technologies for new materials. $^{5}$

\section{GROWTH PROCESS}

This section gives a short description of the growth setup and growth process, focusing on aspects relevant for the present study. The feedstock in the form of silicon granulate plays a crucial role in the Si-GC process. We use commercially available granulate (from two vendors-A and B) produced in a fluidized bed reactor from silane gas (see, e.g., Ref. 6) with a particle diameter up to about $5 \mathrm{~mm}$. Before the start of the growth process, granulate is filled into a quartz container as shown in Fig. 1a. The growth setup discussed in the present study is intended for crystal diameters up to about $60 \mathrm{~mm}$. The inner container diameter is $29 \mathrm{~cm}$, and the initial charge reaches about $8 \mathrm{~kg}$ (resulting from container volume of $0.005 \mathrm{~m}^{3}$ and granulate bulk density of $1500 \mathrm{~kg} / \mathrm{m}^{3}$ ). The container with granulate is moved close to a highfrequency inductor with an inner hole of $80 \mathrm{~mm}$, working at about $2 \mathrm{MHz}$. At first, the induced eddy currents heat up the graphite susceptor placed in the middle of the inductor. At higher temperatures, the eddy currents are induced in the granulate directly, and a melt pool below the inductor is created. It is separated from the quartz container by a stable layer of solid Si granulate with a thickness of a few centimeters. After the melting process is finished, a monocrystalline seed is moved through a hole in the middle of the susceptor to touch the melt surface. Then, the seed and the susceptor are moved upward, and a crystal is pulled out of the melt as in CZ growth. The typical growth velocity is $2 \mathrm{~mm} /$ min. During the growth, the melt volume is kept constant by continuous replenishment with solid granulate through a hole in the inductor.

For a discussion of the origin of impurities incorporated during crystal growth, the materials used in the growth setup must be considered as potential sources of contamination. The watercooled steel vessel of the growth furnace and the copper inductor (including the attached parts for granulate replenishment) are similar to the FZ process and are kept near ambient temperature by water-cooling. These parts probably do not cause any significant contamination. The same can be assumed about the quartz container which remains at relatively low temperatures of about $600^{\circ} \mathrm{C}$. The temperature of the graphite susceptor may reach $1600^{\circ} \mathrm{C}$ during the melting process, and temperatures above $1000^{\circ} \mathrm{C}$ are experienced also by the heat shields and the holding bars made of molybdenum above the susceptor. To investigate possible contamination with carbon and molybdenum, a

\section{Growth setup}

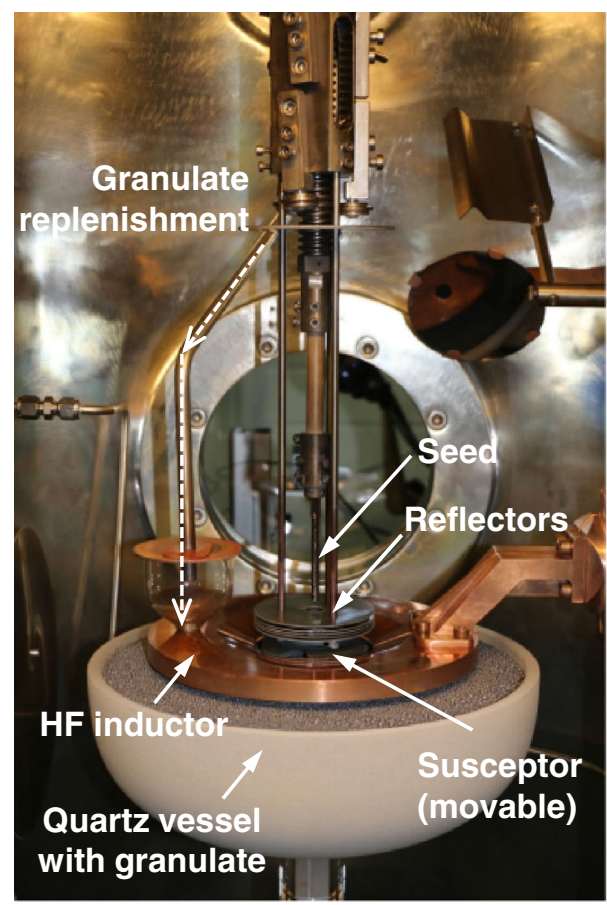

(a)

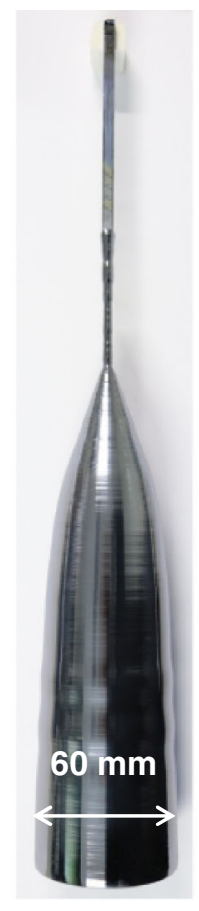

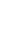

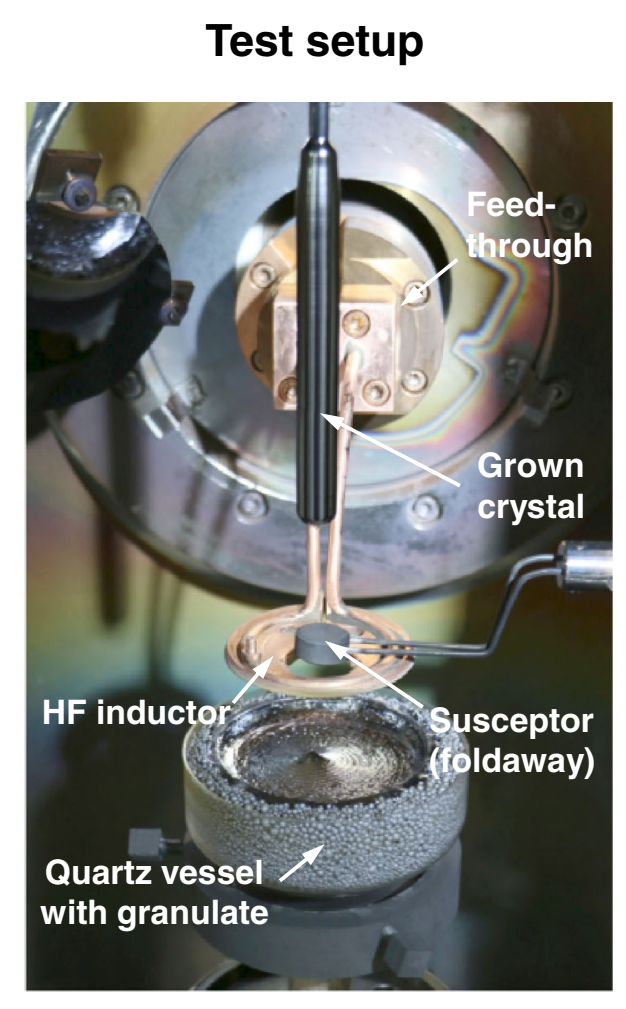

(b)

Fig. 1. Experimental setups for silicon crystal growth from a granulate crucible: growth setup for process development (a) and test setup for feedstock purity testing (b). Typical examples of the grown crystals are shown. 
Table I. Overview of characterized crystals

\begin{tabular}{|c|c|c|c|c|c|c|}
\hline ID & $\begin{array}{l}\text { Granulate } \\
\text { vendor }\end{array}$ & Setup & $\begin{array}{c}\text { Dimensions, } \\
\text { mm }\end{array}$ & $\begin{array}{l}\text { Doping/resis- } \\
\text { tivity (300 K) }\end{array}$ & $\begin{array}{l}\text { Dislocation- } \\
\text { free? }\end{array}$ & $\begin{array}{l}\text { Applied characterization } \\
\text { methods }\end{array}$ \\
\hline 3773 & A & Test & Ø13, L120 & $(p, 150 \Omega \mathrm{cm})$ & No & ICP-MS, FTIR \\
\hline 3774 & B & Test & $\varnothing 13, \mathrm{~L} 120$ & $(p, 150 \Omega \mathrm{cm})$ & No & ICP-MS, FTIR \\
\hline $\mathrm{E} 43$ & $\mathrm{~B}$ & Growth & Ø55, L105 & $(p, 10 \Omega \mathrm{cm})$ & No & ICP-MS, FTIR, LST, EPD \\
\hline $\mathrm{E} 45$ & $\mathrm{~A}$ & Growth & Ø60, L175 & $n, 1.5 \Omega \mathrm{cm}$ & No & $\begin{array}{l}\rho(\mathrm{r}, \mathrm{z}), \text { ICP-MS, FTIR, IR-Trans., } \\
\text { Lang, XRT, EPD, MDP, DLTS }\end{array}$ \\
\hline $\mathrm{E} 49$ & A & Growth & Ø58, L210 & $n, 14 \Omega \mathrm{cm}$ & Partly & ICP-MS, EPD, MDP \\
\hline $\mathrm{FZ}$ & $\mathrm{B}$ & Growth + FZ & Ø57, L330 & $(n,>150 \Omega \mathrm{cm})$ & Yes & ICP-MS, MDP \\
\hline
\end{tabular}

Typical resistivity measured in the middle part of the crystal is given, "()" denotes unintentional doping. The FZ crystal was obtained by using a Si-GC crystal (similar to E43) as a feed rod in an FZ growth process

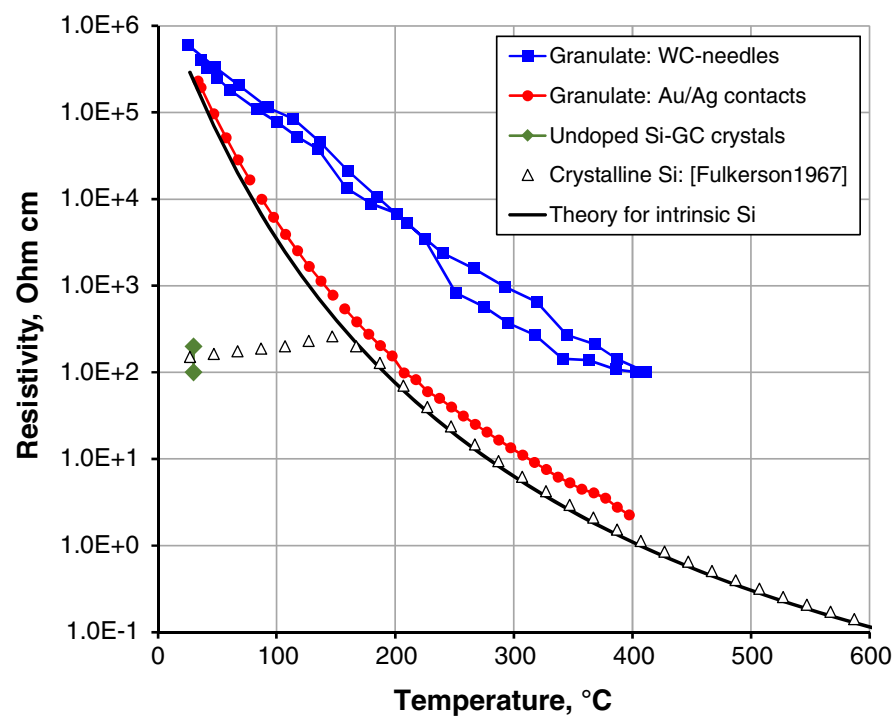

(a)

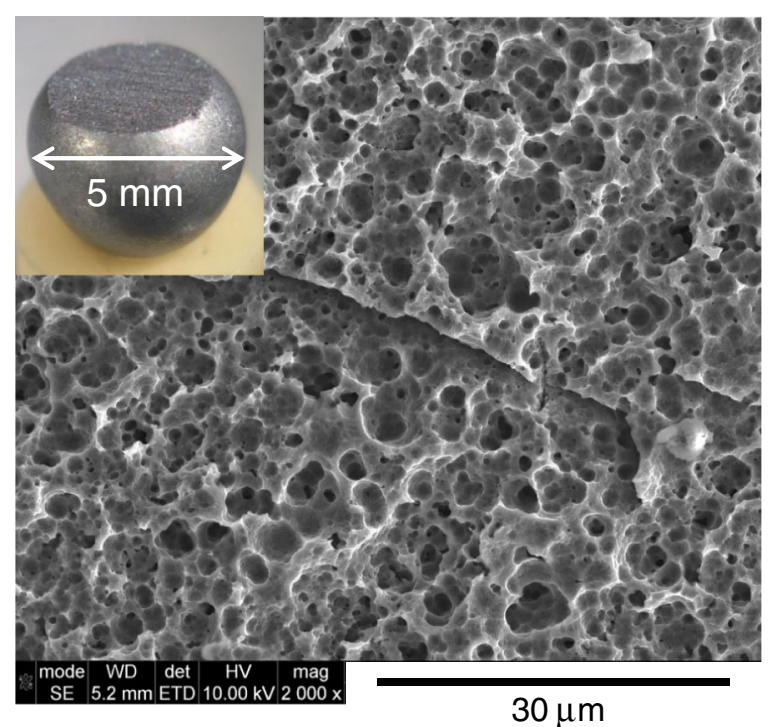

(b)

Fig. 2. Granulate feedstock: (a) temperature-dependent electrical resistivity measured on a single granulate particle (a comparison with crystalline silicon in the literature is given, and the typical resistivity level for undoped Si-GC crystals is indicated); (b) scanning electron microscopy (SEM) image of typical granulate microstructure showing also a photograph of the ground particle.

simplified test setup was developed-without any molybdenum parts and with a small graphite susceptor used only in the very beginning of melting (see Fig. 1b). This setup enables the growth of crystals with diameters up to $15 \mathrm{~mm}$, but the growth of a thin neck is not possible.

\section{CHARACTERIZATION RESULTS AND DISCUSSION}

Crystals from various development stages of the Si-GC process have been investigated in the present study. Table I provides an overview of the main process and material parameters for these crystals and summarizes the characterization methods applied. The results are discussed in detail in the following sections.

\section{Electrical Resistivity and Microstructure of Si Granulate}

The temperature-dependent electrical resistivity of feedstock granulate particles in their raw form plays a crucial role in the inductive melting process. A sufficiently low resistivity is needed to induce eddy currents (i.e., heat) in the granulate and create a large melt pool below the inductor as described in the previous section. Therefore, resistivity measurements on single granulate particles were performed using a commercial Hall effect measurement system (LakeShore HMS 7504 equipped with an oven sample module) up to temperatures of about $400^{\circ} \mathrm{C}$. The granulate particle was ground down to a thin round plate of about $0.5 \mathrm{~mm}$ thickness. After etching with $\mathrm{CP}^{7}$ for about $90 \mathrm{~s}$, four $\mathrm{Au}$ wires were attached using silver glue to obtain a van der 
Pauw configuration. The results of resistivity measurements are compared to literature data for crystalline silicon in Fig. 2a. Experimental results were taken from Ref. 8, while theoretical calculation for intrinsic silicon was based on Ref. 9. It can be observed that the temperature-dependent effective electrical resistivity of silicon granulate particles is very close to that of intrinsic silicon. Consequently, the resistivity of granulate at room temperature reaches a high value of about $3 \cdot 10^{5} \Omega \mathrm{cm}$. Very similar results were obtained for granulate from both vendors considered in this study.

Additional tests were performed with a standard setup for silicon resistivity with a four-point probe of tungsten carbide (WC) needles at a distance of $0.635 \mathrm{~mm}$, allowing appropriate electrical contacts to silicon through the native oxide layer. ${ }^{10}$ The round granulate particle was ground down to obtain a flat surface and placed in a miniature copper heater. The obtained temperature-dependent resistance was multiplied with a correction factor of typically 0.26 (determined by numerical simulations of the $3 \mathrm{D}$ electric potential distribution in the ground-down granulate particle) to obtain bulk resistivity. Figure $2 \mathrm{a}$ shows that measurements with $\mathrm{Au}$ wires and WC needles agree well at room temperature. However, the resistivity at $400^{\circ} \mathrm{C}$ is overestimated by a factor of 100 in case of WC needles (i.e., with point contacts between WC needles and granulate surface).

Since undoped crystalline samples show a significantly lower resistivity than raw granulate (see next section and Table I), obviously, the microstructure of granulate particles might also influence their effective electrical resistivity. Granulate particles embedded in an epoxy resin were polished with a slurry containing colloidal silica particles and etched with various solutions such as CP $6,{ }^{7}$ Secco,${ }^{11}$ Sirtl, ${ }^{12}$ and Wright. ${ }^{13}$ The obtained microscopic images were ambiguous; for example, Sirtl etch produced elongated structures up to a length of about $100 \mu \mathrm{m}$, which had a concentric symmetric arrangement and resembled grooves. A polished surface of a granulate particles was also observed with an electron microscope in secondary electron (SE) mode. Figure $2 \mathrm{~b}$ indicates a porous structure on the micrometer scale, but does not allow us to identify any grain or crystallite size. To distinguish between amorphous and crystalline structures, we milled granulate to a fine powder and obtained a diffractogram using a Seifert XRD 3003 device. $\mathrm{Cu}-$ $\mathrm{K} \alpha$ radiation and the Bragg-Brentano geometry in $\theta-\theta$-mode were applied. The results showed no significant amorphous part, but peak broadening was visible when compared to a reference sample obtained from monocrystalline FZ silicon. Hence, we may qualitatively conclude that silicon granulate has a nanocrystalline structure on the scale of $100 \mathrm{~nm}$ or smaller, which is overlaid by a porous microstructure on the scale of $1-100 \mu \mathrm{m}$. It should be noted that the density of granulate is still very

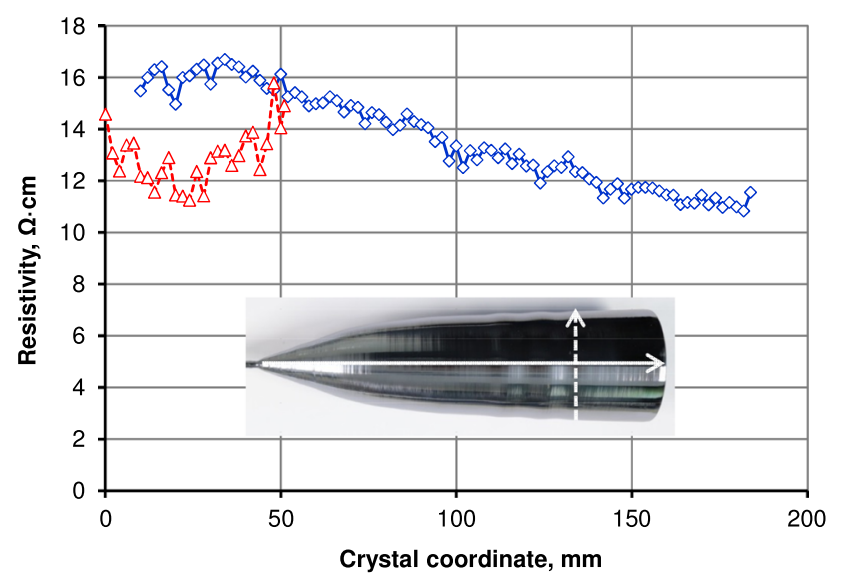

Fig. 3. Resistivity distribution measured on a longitudinal section of the crystal E49 in axial and radial directions as indicated by the arrows.

close (roughly estimated at least 95\%) to crystalline silicon.

It is known from the literature that grain boundaries in polycrystalline silicon may increase the effective electrical resistivity by the formation of deep defect or trap states. ${ }^{14}$ Similar states are present at the void surfaces and form space charge regions extending into the semiconductor. The width of these regions, which are depleted of free carriers, depends on the (intentional or unintentional) doping level. The effect is that the macroscopically measured resistivity of the Si granulate may be much higher than that of homogeneous crystalline material, in some cases even higher than the intrinsic resistivity of Si. This effect obviously dominates the granulate resistivity in the range above about $100 \Omega \mathrm{cm}$, i.e., at temperatures below $200^{\circ} \mathrm{C}$ (see Fig. 2a).

Finally, it should be noted that FZ feed rod material is also produced from silane gas in a process similar to that for silicon granulate. A previous study ${ }^{15}$ revealed a dendritic microstructure on the scale of $100 \mu \mathrm{m}$, and x-ray diffraction confirmed crystalline cubic silicon.

\section{Dopant Concentration and Crystal Resistivity}

It is an interesting fact that the first application of the Si-GC method ${ }^{3}$ was purity analysis of silicon granulate by producing small crystalline samples. The typical resistivity of undoped crystals in the present study was about $150 \Omega \mathrm{cm}$. Inductively coupled plasma mass spectrometry (ICP-MS) measurements (see next section) show a total dopant level of about $3 \cdot 10^{14} \mathrm{~cm}^{-3}$ both for $p$-type and $n$ type, which corresponds to $43 \Omega \mathrm{cm}$ and $15 \Omega \mathrm{cm}$, respectively, and thus indicates a significant compensation effect.

Crystals in the present Si-GC growth setup were doped using $\mathrm{PH}_{3}$ gas, where the duration and the flow rate were adjusted to obtain $n$-type conduction in the range $1-20 \Omega \mathrm{cm}$. Resistivity measurements 


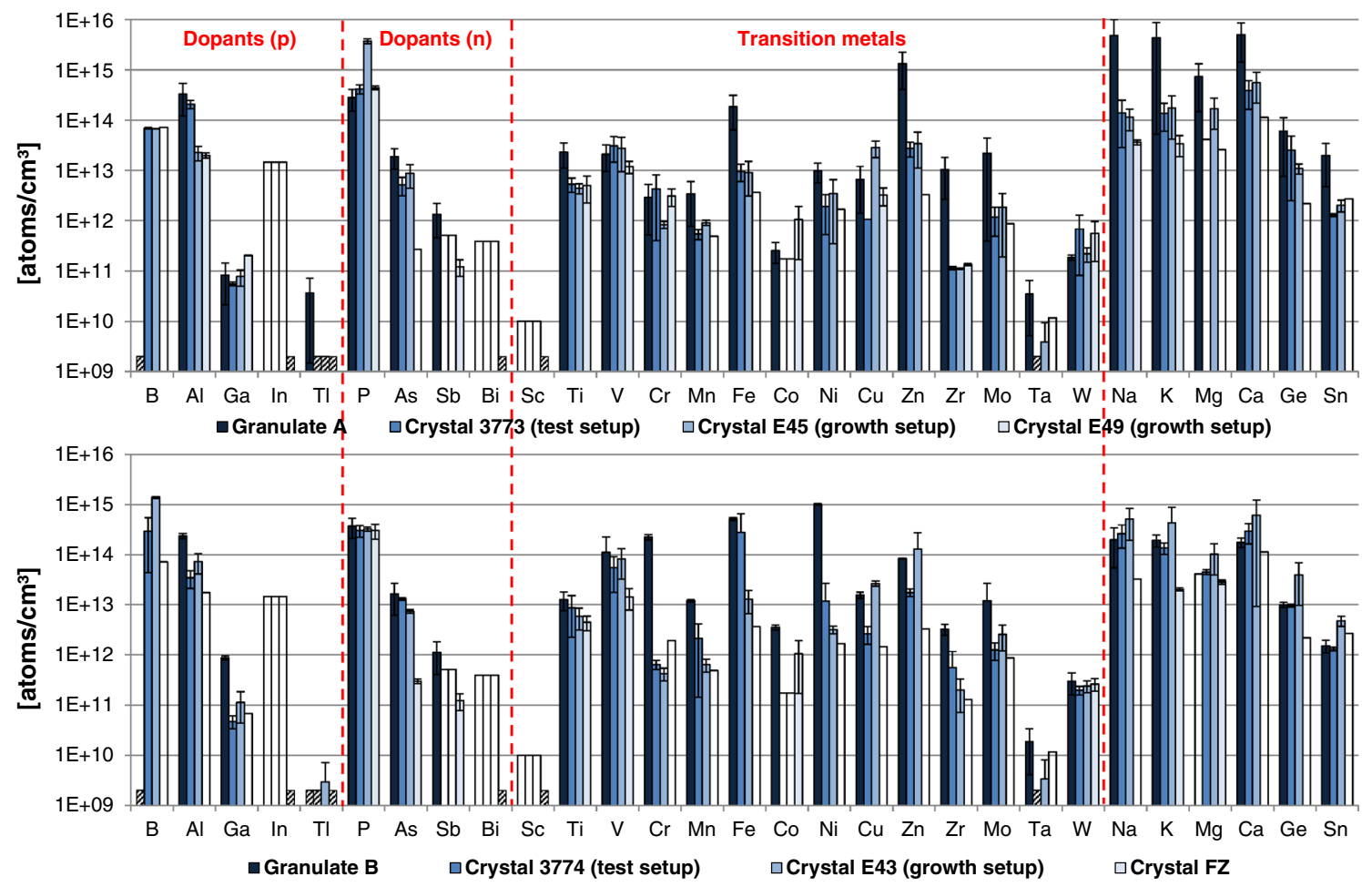

Fig. 4. ICP-MS measurements of impurities in granulate and crystals. Colored bars and error indicators show the measured concentration and its variation (from two to three samples). Textured or transparent bars indicate missing measurements or values below the limit of detection (it may slightly vary between samples), respectively (Color figure online).

in Fig. 3 show a typical example with decreasing resistivity over crystal length between $16 \Omega \mathrm{cm}$ and $11 \Omega \mathrm{cm}$. In a continuous process (similar to the $\mathrm{FZ}$ process) with replenishment of undoped (or largely compensated) feedstock, the resistivity should actually decrease if we consider the segregation effect (coefficient $k_{0}=0.35$ for phosphorus ${ }^{16}$ ) and assume a closed system (i.e., the melt reaches an equilibrium according to the $\mathrm{PH}_{3}$ contents in the gas atmosphere). Therefore, the decrease can be attributed to changes in the melt volume or $\mathrm{PH}_{3}$ concentration in the gas atmosphere (which could be easily adjusted by changing the dopant inflow). The radial resistivity profile of the crystal in Fig. 3 shows a lower resistivity (higher dopant concentration) in the center. This effect can be explained by the melt flow, where a flow along the crystallization interface towards the center has been observed in numerical calculations.

Consequently, gas doping also allows us to achieve the desired doping profile for the case with significant dopant levels and compensation in the feedstock.

\section{Impurities}

Impurity concentrations in both the raw granulate and grown crystals were investigated using ICP-MS at Fraunhofer Center for Silicon Photovoltaics (CSP). ${ }^{17}$ Figure 4 shows a summary for granulate feedstock from two vendors and the corresponding crystals grown in the test and growth setups. Crystal samples were prepared from crystal end sections. In all cases, measurements from two to three identical samples were used to determine the average value and the variation. Since dopants were analyzed in the previous section, here we focus on transition metals, which play a significant role with respect to further applications of Si-GC material. It can be observed that the highest concentrations in crystals exceeding $10^{13} \mathrm{~cm}^{-3}$ are reached for $\mathrm{V}, \mathrm{Fe}$, $\mathrm{Cu}$, and $\mathrm{Zn}$. The sum of all detected transition metal concentrations reaches $2 \cdot 10^{15} \mathrm{~cm}^{-3}$ in granulate feedstock, $8 \cdot 10^{13}-4 \cdot 10^{14} \mathrm{~cm}^{-3}$ in the crystals from the test setup, $3 \cdot 10^{13}-3 \cdot 10^{14} \mathrm{~cm}^{-3}$ in the crystals from the growth setup, and $2 \cdot 10^{13} \mathrm{~cm}^{-3}$ in the FZ crystal. Obviously, there are some differences in the impurity concentrations for various crystals and for both vendors of granulate. However, a more detailed analysis would require a comprehensive evaluation of the precision of concentration measurements close to the limit of detection, which is beyond the scope of this study.

It is important to note that the segregation coefficients of most transition metals in silicon are in the range $k_{0}=10^{-6}-10^{-4}$ (a higher value of $k_{0}=10^{-3}$ is observed for $\mathrm{Cu}$ ). ${ }^{18}$ If we consider a continuous process with the impurity in the feedstock (concentration $C_{0}$ ) and assume complete melt mixing, the following expression can be derived for the axial concentration profile $C_{\text {crys }}(z)$ in the crystal 

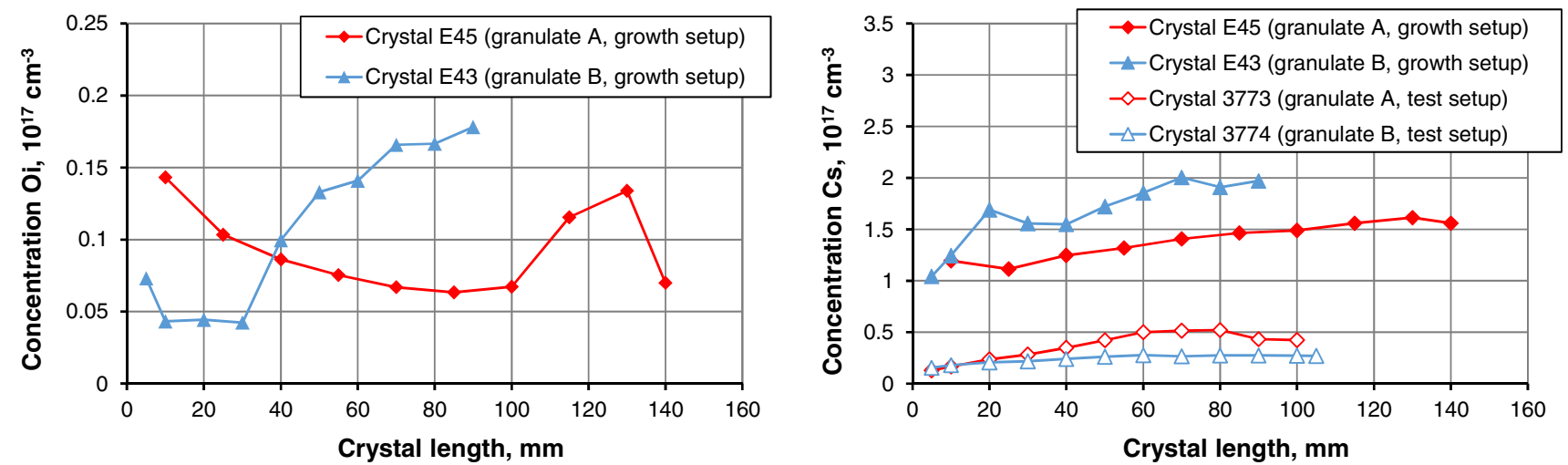

Fig. 5. Axial profiles of carbon and oxygen concentration measured by FTIR in the middle of longitudinal cuts.

$$
C_{\text {crys }}=C_{0}\left[1-e^{-k_{0} \frac{z}{L}}\left(1-k_{0}\right)\right]
$$

where $L$ is the (approximately constant) ratio between melt volume and crystal cross section. ${ }^{19}$ For $k_{0} \ll 1$ and $z / L \ll 1$ (i.e., crystal volume smaller than melt volume), this expression can be simplified to $C_{\text {crys }} \approx C_{0} k_{0}$. Consequently, the concentration in the crystal should decrease by 4-6 orders of magnitude compared to the concentration in the feedstock granulate. However, the total concentration of all transition metals decreases only by 1-2 orders of magnitude, and only a few metals such as Fe show a distinct decrease in several cases in Fig. 4. High metal concentrations in silicon crystals, i.e., apparently high values of the effective segregation coefficient, have been attributed to the presence of undissolved metallic particles in the feedstock and melt or to the precipitation of metals at extended defects, see, e.g., Ref. 20, 21.

Finally, it should be noted that some crystals from the growth setup show a slight increase in $\mathrm{Cu}$ concentration which could be related to the inductor. Concentration of Mo is not higher than that in the test setup within the uncertainty of the measurement. The elements $\mathrm{Na}, \mathrm{K}, \mathrm{Mg}$, and $\mathrm{Ca}$ show high concentrations exceeding $10^{14} \mathrm{~cm}^{-3}$ in several cases, but possible sources and consequences for material quality have not been investigated in the present study yet.

Further impurities such as carbon and oxygen were determined using Fourier transform infrared (FTIR) absorption spectroscopy with a Bruker IFS$66 \mathrm{~V}$ device at room temperature. Line scans on $2 \mathrm{~mm}$-thick samples are summarized in Fig. 5. Interstitial oxygen concentration $\left(O_{\mathrm{i}}\right)$ was below $2 \cdot 10^{16} \mathrm{~cm}^{-3}$ for the growth setup and under the detection limit for the test setup. Substitutional carbon concentration $\left(C_{\mathrm{s}}\right)$ reached $2 \cdot 10^{17} \mathrm{~cm}^{-3}$ in the growth setup but stayed below $5 \cdot 10^{16} \mathrm{~cm}^{-3}$ in the test setup. Consequently, oxygen concentration is almost on the level of floating zone $\mathrm{Si}$, while carbon concentration in the growth setup comes close to the solubility limit of $3.5 \cdot 10^{17} \mathrm{~cm}^{-3}$ in silicon. Since carbon concentration in the test setup is much smaller, the most likely source of carbon in the growth setup is graphite susceptor, which is the only part containing carbon and used at high temperatures (during the melting).

The high carbon concentration in the crystal may cause the formation of $\mathrm{SiC}$ inclusions. ${ }^{22}$ This possibility was investigated using infrared transmission imaging with an Olympus MX-61 transmission microscope on $2 \mathrm{~mm}$-thick longitudinal sections of the crystals. This method enables the detection of particles with diameters typically greater than $2 \mu \mathrm{m}$. The map in Fig. 6 a shows a relatively homogeneous distribution over the crystal length with a particle density of about 300 particles $/ \mathrm{cm}^{3}$ (60 particles $/ \mathrm{cm}^{2}$ for a sample thickness of $2 \mathrm{~mm}$ ), detected above $7 \mu \mathrm{m}$. As can be seen in the microscopic image, the particles typically have a round shape. To detect smaller inclusions, we applied laser scattering tomography (LST) with a 1064-nm $\mathrm{Nd}$ :YAG laser. ${ }^{23} \mathrm{~A}$ longitudinal section of $2 \mathrm{~mm}$ thickness was illuminated on its polished edge surface while observing the scattered light with a Si CCD camera in the perpendicular plane. The resulting image in Fig. $6 \mathrm{~b}$ reveals about 7000 scatterers on a sample surface of $55 \times 4 \mathrm{~mm}^{2}$, which corresponds to an average density of 3000 scatterers $/ \mathrm{cm}^{2}$. The distribution of these scatterers seems to follow the shape of the crystallization interface. This effect may have been caused by formation of carbon precipitates in the melt and building into the crystal as $\mathrm{SiC}$ inclusions at the growth interface.

\section{Structural Defects}

The Si-GC method aims to grow dislocation-free crystals and applies the Dash neck technique ${ }^{24}$ similarly to $\mathrm{CZ}$ growth. The growth is continued from the monocrystalline seed with a small crystal diameter under $5 \mathrm{~mm}$ for at least several centimeters, which is achieved by increasing the pulling velocity to about $10 \mathrm{~mm} / \mathrm{min}$. Similarly to $\mathrm{FZ}$ and CZ growth, in most cases, Si-GC crystals showed 


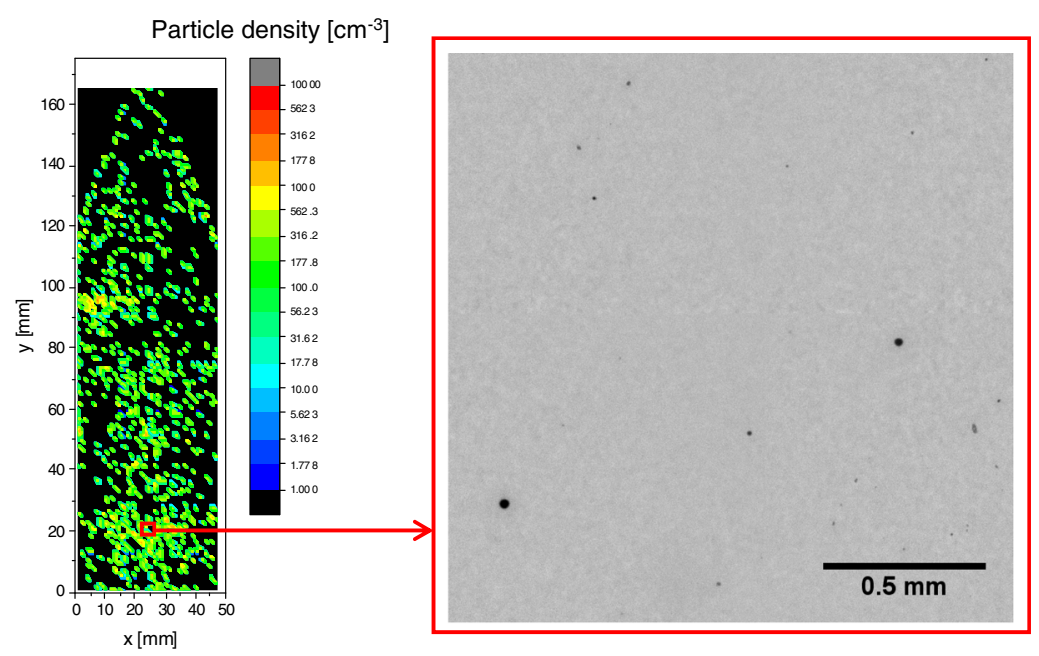

(a)

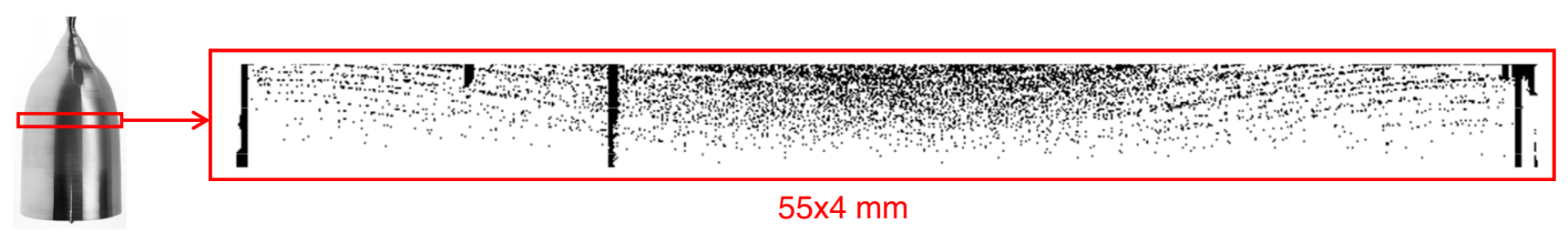

(b)

Fig. 6. Inclusions in crystals: (a) infrared transmission map of a longitudinal cut for crystal E45; (b) LST image for a 4 mm-long part of a longitudinal cut for crystal E43.
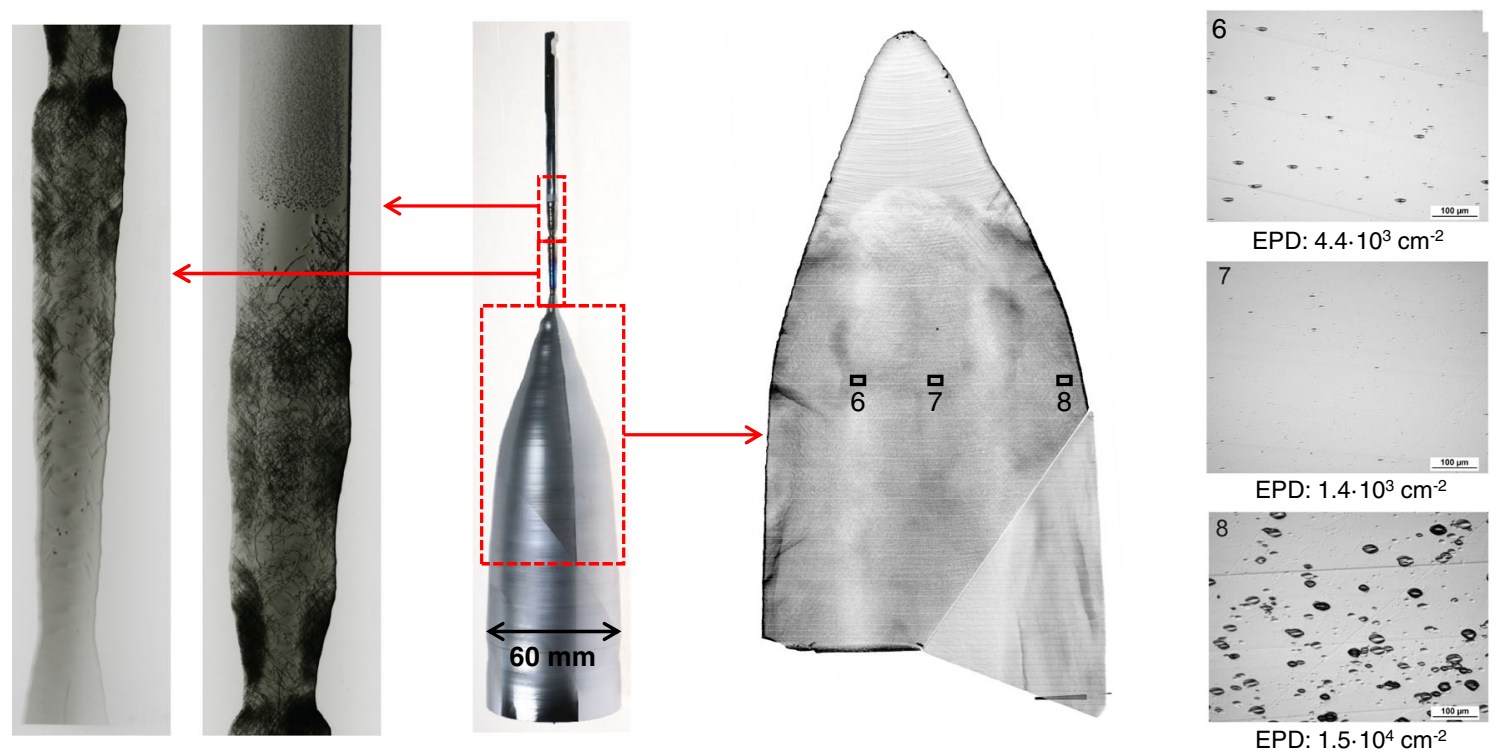

Fig. 7. Structural defects in crystal E45: photo of the crystal indicating the investigated areas (middle); Lang topogram of the thin neck (left); transmission topogram of a longitudinal cut (right) with microscopic images of etch pits (marked locations 6-8).

four growth ridges (for growth in $<100>$ direction) at least in the first half of the crystal. This usually indicated that the crystal was growing as a single crystal, but not necessarily that is was free of dislocations. While it is often possible to evaluate the thin necks from FZ crystals by looking on the etched surface under an optical microscope for etch pits, this technique turned out to be unreliable for Si-GC crystals. It was not possible to distinguish etch pits from other defects or impurities on the 
surface. Therefore, the thin neck was cut and polished to a thin plate with $\{100\}$ surface orientation and $0.5 \mathrm{~mm}$ thickness. This sample was investigated using x-ray Lang topography with the 004 reflex and Mo-K $\alpha_{1}$ radiation, see, e.g., Ref. 25 . The resulting image in Fig. 7 shows a rapid increase in dislocation density when neck diameter changes abruptly, followed by a continuous outgrowth of dislocations in the next section until the crystal obviously became free of dislocations.

Since the Lang topogram was limited to small samples, the crystal was investigated using x-ray transmission topography with a Rigaku XRTmicron tool using the 004 reflex. ${ }^{26}$ Again, we consider a longitudinal cut of $2 \mathrm{~mm}$ thickness and $\{110\}$ surface orientation. While only doping striations can be distinguished in the first half of the cone (due to dopant incorporation causing local stress) in Fig. 7, structural defects create new contrasts in the remaining crystal. Increased defect density appears both at the rim of the crystal and in the central part, creating a W-shaped radial profile (the low-defect zone is a hollow cylinder in three dimensions). It should be noted that the XRT image is disturbed by twinning and by crystal cracking so that only the top part of the crystal could be evaluated.

A quantitative evaluation of structural defects was performed by using etching methods and subsequent investigation with an optical microscope having differential interference contrast (DIC). On a longitudinal section with a $\{110\}$ surface, the best results were achieved using a $\mathrm{HNO}_{3}-\mathrm{HF}-$ $\mathrm{CH}_{3} \mathrm{COOH}$ (2:1:4) solution. ${ }^{27}$ This etch does not belong to the most popular ones for silicon, but it revealed distinct etch pit shapes and also worked well for other surface orientations. The examples shown in Fig. 7 confirm a higher etch pit density (EPD) at the rim, reaching $1.5 \cdot 10^{4} \mathrm{~cm}^{-2}$ (up to $2 \cdot 10^{5} \mathrm{~cm}^{-2}$ in the lower part of the crystal). However, the central part at the chosen location seems to have the lowest defect density, contradicting the qualitative impression from the XRT image. Further analysis of the etched $\{110\}$ surface revealed that there are two distinct types of etch pits:
- Deep pits with a typical pyramidal shape and a clearly visible bottom point representing a dislocation intersecting the surface. Their size increases with increasing etching time.

- Shallow pits with an elliptical shape without a bottom point. Already short etching time of 5 min creates a pit size up to $20 \mu \mathrm{m}$ (while the normal etch pits reach only about $2 \mu \mathrm{m}$ ). However, their extension over the sample depth is currently not clear.

While the deep pits most likely can be attributed to dislocations, the origin of the shallow pits is not clear. They could be associated with voids, stacking faults, inclusions, precipitates, etc. (see, e.g., Ref. 28). Such assumptions could be confirmed with transmission electron microscopy, but this is quite challenging due to the rather low defect density of $10^{5} \mathrm{~cm}^{-2}$ or less. Both etch pits obviously have different but overlapping distributions.

Figure 8 gives a closer view on the etch pits. While $\{110\}$ longitudinal sections show the presence of both types of etch pits, we observed on $\{100\}$ longitudinal sections mainly the deep etch pits from dislocations. The picture in Fig. 8b demonstrates that the shallow pits are obviously independent of the etching time, while the deep pits are smaller, and their size is nearly proportional to the etching time. Analysis of several crystals indicated that the crystals E43 and E45 show a similar etch pit density distribution with a W-shaped radial defect density profile. The crystal E49 did not contain any deep pits in the upper part of the crystal.

A closer look at the outer surface of the crystal E49 revealed several positions where small particles are attached in the bottom part, causing at first slip lines and then grain boundaries, see Fig. 9a. It can be assumed that the first half of this crystal was growing free of dislocations, until a small unmolten granulate particle on the melt surface got into contact with the growth interface and induced dislocations. Figure 9 provides defect maps of both types of etch pits on a $\{110\}$ longitudinal cut. These

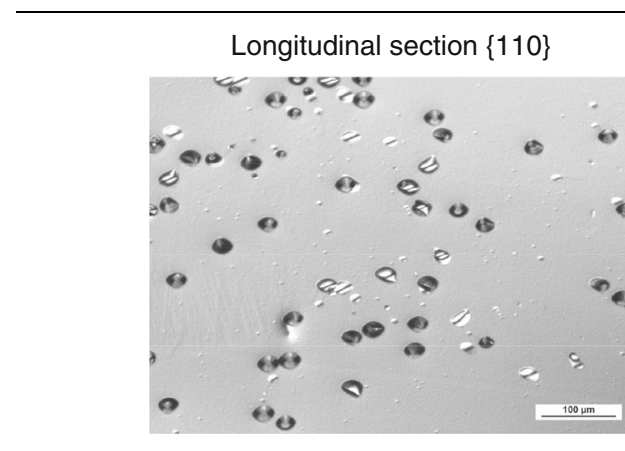

(a)
Longitudinal section $\{110\}$

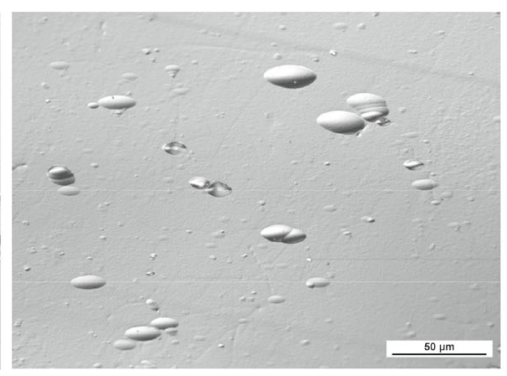

(b)

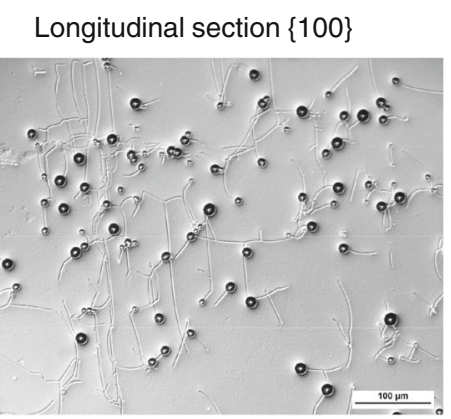

(c)

Fig. 8. Micrographs of the etch pits for the crystal $E 43$ for longitudinal cuts of $\{110\}$ and $\{100\}$ orientations (a-c). In image (b), the etching time of the sample was 10 times shorter than in image (a). In all cases, positions close to the rotation axis in the bottom part of the crystal were analyzed. The growth direction in the images points downward. 


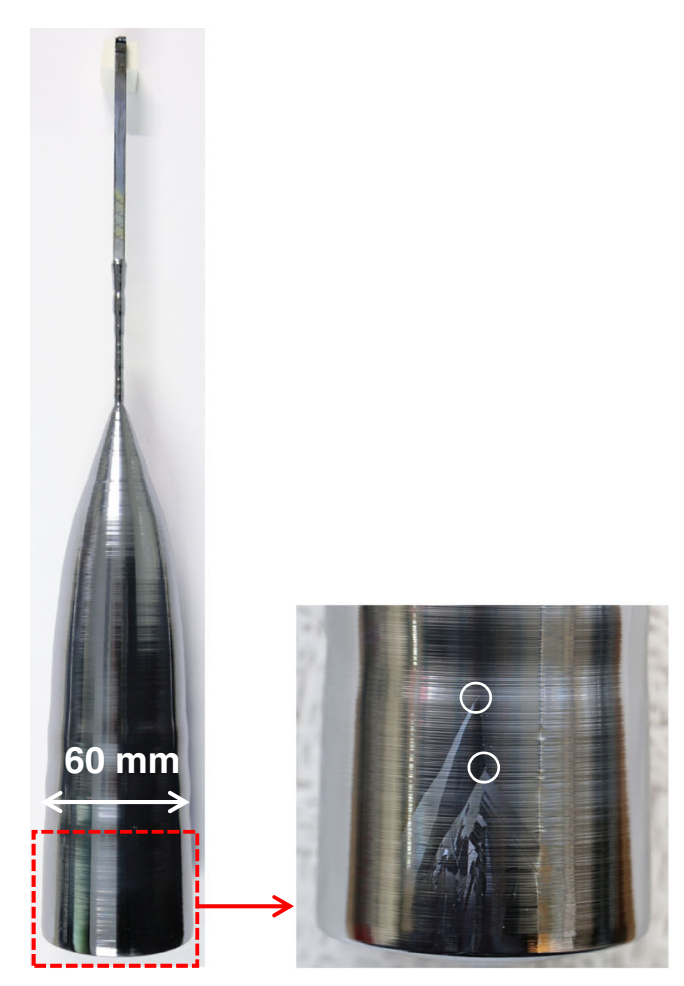

(a)

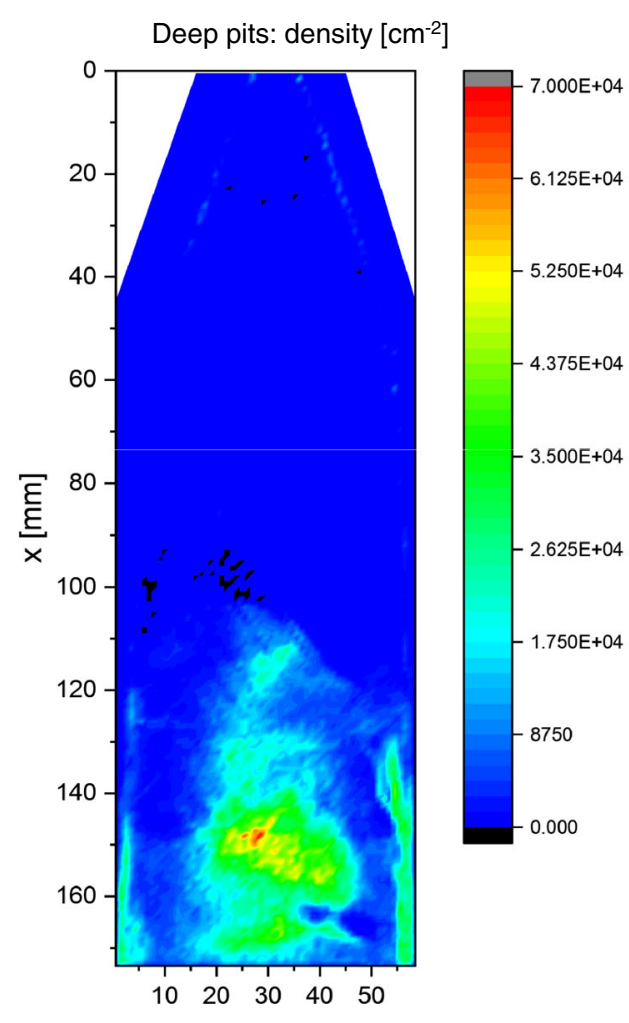

(b)

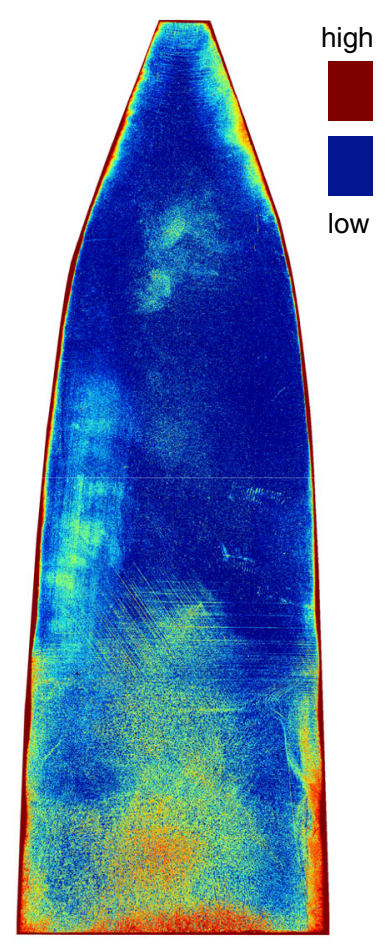

(c)

Fig. 9. Structural defects in crystal E49: photographs of the crystal surface (a) and maps of both types of etch pits on a $\{110\}$ longitudinal cut (b, c).

were obtained with an Olympus MX-61 reflection microscope equipped with a motorized and automated sample table. The microscope images were evaluated using a gray value threshold. The resulting dark spots were counted if their geometry matched certain specifications (area 8-200 $\mu \mathrm{m}^{2}$, circularity $>0.7$, solidity $>0.7$ ); all other dark areas were ignored. From the etch pit count, a density map was generated. It can be seen that both etch pit types demonstrate a W-shaped radial density profile in the bottom part of the crystal. Furthermore, the shallow etch pits are also present in the upper (dislocation-free) part of the crystal. Note that the shallow etch pits could be evaluated only qualitatively.

\section{Carrier Lifetime}

Carrier lifetime is not only an essential material quality parameter for silicon photovoltaics but also an extremely sensitive indicator of (electrically active) impurities and structural defects. Carrier lifetime maps for longitudinal cuts of crystals were obtained using the microwave-detected photoconductivity (MDP) technique using an MDPmap device from Freiberg Instruments. ${ }^{29}$ This method reaches a penetration depth of $100 \mu \mathrm{m}$ in silicon with a laser wavelength of $980 \mathrm{~nm}$. To assess bulk carrier lifetime, the surface recombination was suppressed by a surface passivation procedure.
The samples were saw-damage etched, RCAcleaned, and passivated with $\mathrm{Al}_{2} \mathrm{O}_{3}$ by atomic layer deposition (ALD) and subsequently annealed at $425^{\circ} \mathrm{C}$. Details and mechanisms of such passivation schemes have been reviewed, e.g., in Ref. 30. It should be noted that simple surface passivation methods such as an HF dip did not lead to significantly higher carrier lifetimes in our tests. Furthermore, we did not observe significant differences in MDP carrier lifetime for various surface preparation methods such as grinding and mechanical or chemo-mechanical polishing before surface passivation.

Figure 10 shows the results of MDP measurements before and after surface passivation for three crystals (discussed in detail in the following paragraphs). The MDP carrier lifetime map of the passivated FZ crystal shows an upper limit of $20 \mathrm{~ms}$ and a minimal value (without edge effects) of at least $5 \mathrm{~ms}$, which is the expected range of reachable surface passivation from our experience. Thus, the MDP maps of crystals E45 and E49 are expected to show dominantly the bulk carrier lifetime because surface recombination is suppressed. The shown unpassivated carrier lifetime maps in comparison to the passivated ones allow understanding the possible improvements of good areas compared to typical unpassivated measurements often used in the literature. Due to the 
Crystal E45 (n-type, $1.5 \Omega \mathrm{cm}$ )

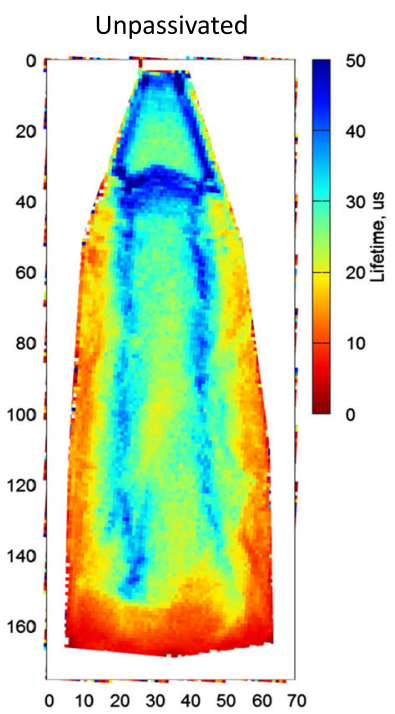

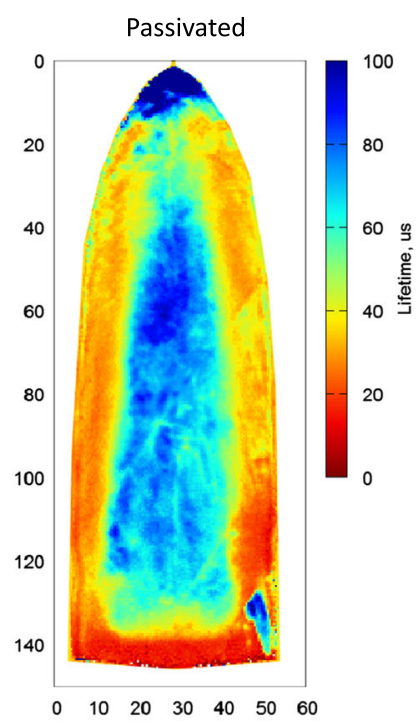

Crystal E49 (n-type, $14 \Omega \mathrm{cm}$ )
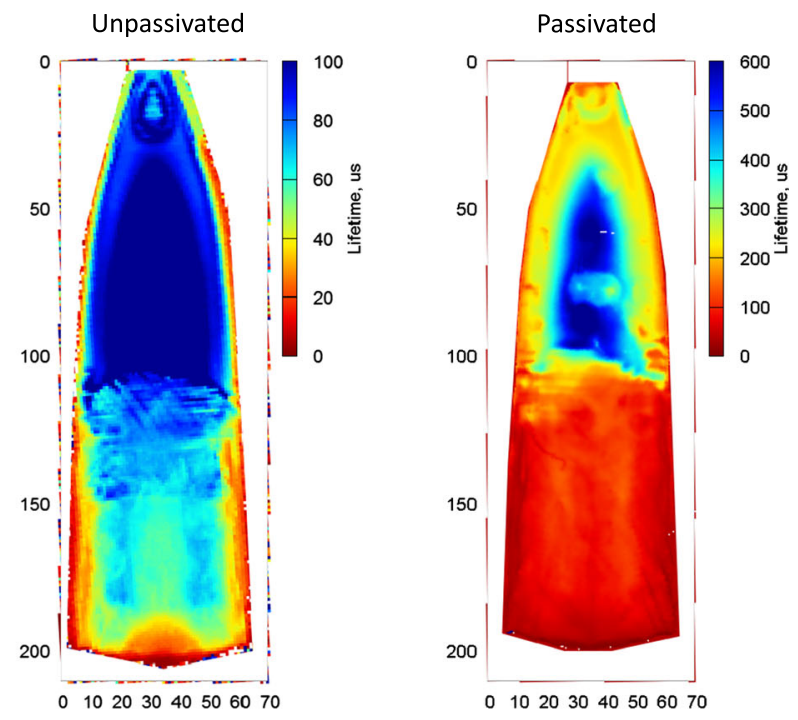

Crystal FZ (n-type, $>150 \Omega \mathrm{cm}$ )

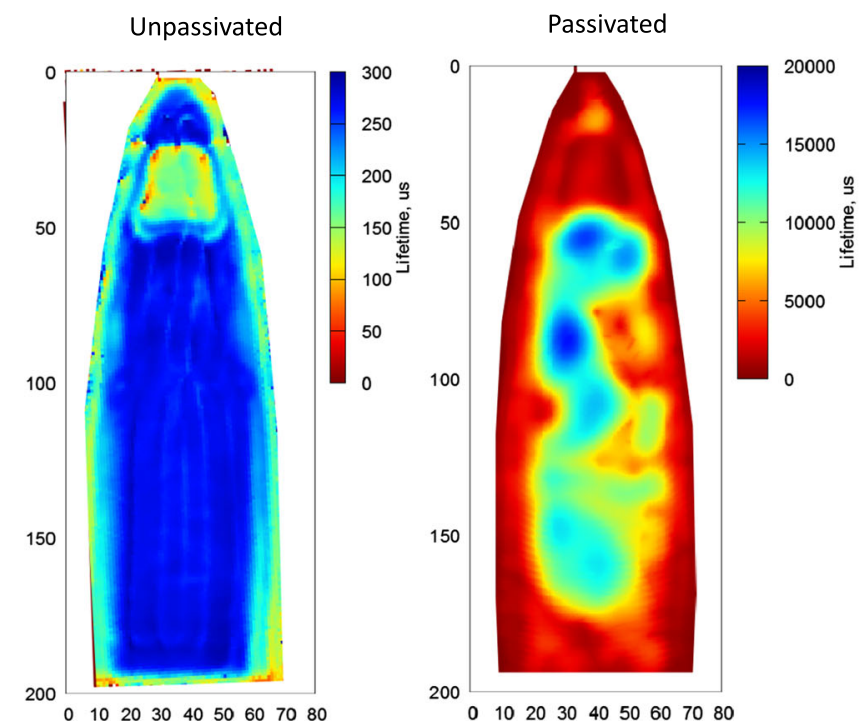

Fig. 10. MDP carrier lifetime map on longitudinal sections for various crystals before and after surface passivation with $\mathrm{ALD} \mathrm{Al}_{2} \mathrm{O}_{3}$. Doping level of each crystal is indicated in the caption. Note that for crystal E45, the radial position of both longitudinal sections is not identical.

different crystal resistivities, we discuss each MDP map separately, because crystal doping influences the carrier lifetime limit of Auger recombination ${ }^{31}$ as well as the Shockley-Read-Hall (SRH) recombination statistics due to changing Fermi level.

For the crystal E45, the obtained carrier lifetime distribution correlates very well with the defect distributions analyzed in the previous section (see Fig. 7). The zones with low defect density correspond to a region of higher carrier lifetime. The maximum carrier lifetime reaches about $100 \mu \mathrm{s}$ in the passivated sample. The changes in the carrier lifetime distribution in the central part of both samples from crystal E45 can be rather attributed to different radial positions of both longitudinal cuts because the region of higher carrier lifetime has a cylindrical shape.

Good correlation between the carrier lifetime distribution and structural defects is also observed for the crystal E49 if we compare Fig. 10 to the dislocation density distribution in Fig. 9. The upper dislocation-free part of the crystal shows a homogeneous carrier lifetime distribution at about $600 \mu \mathrm{s}$ for the passivated sample. The bottom part of the crystal reaches a carrier lifetime of about $100 \mu \mathrm{s}$ in the center and $130 \mu \mathrm{s}$ in the low-defect zone. These regions correspond to etch pit (dislocation) densities of about $4 \cdot 10^{4} \mathrm{~cm}^{-2}$ and $1 \cdot 10^{4} \mathrm{~cm}^{-2}$, respectively 


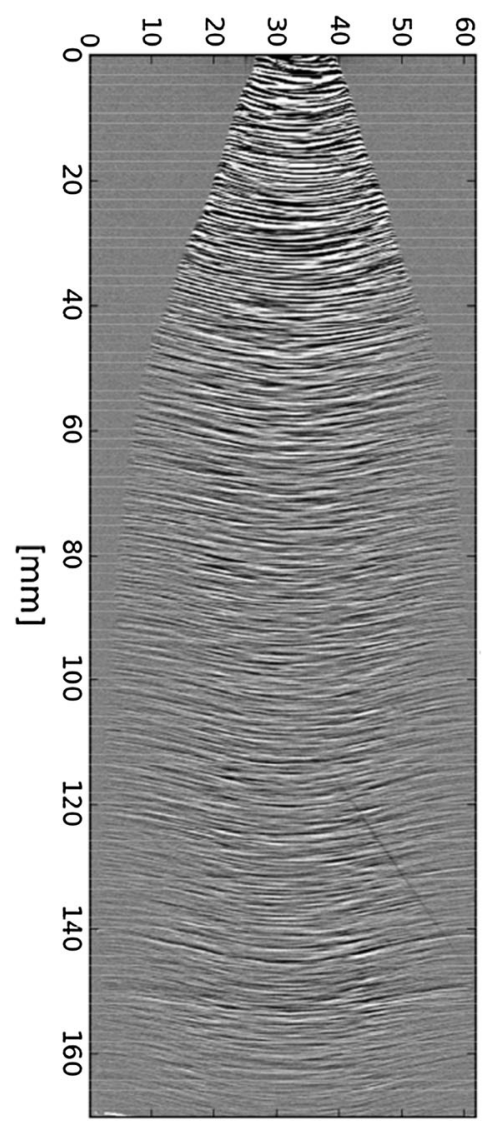

(a)

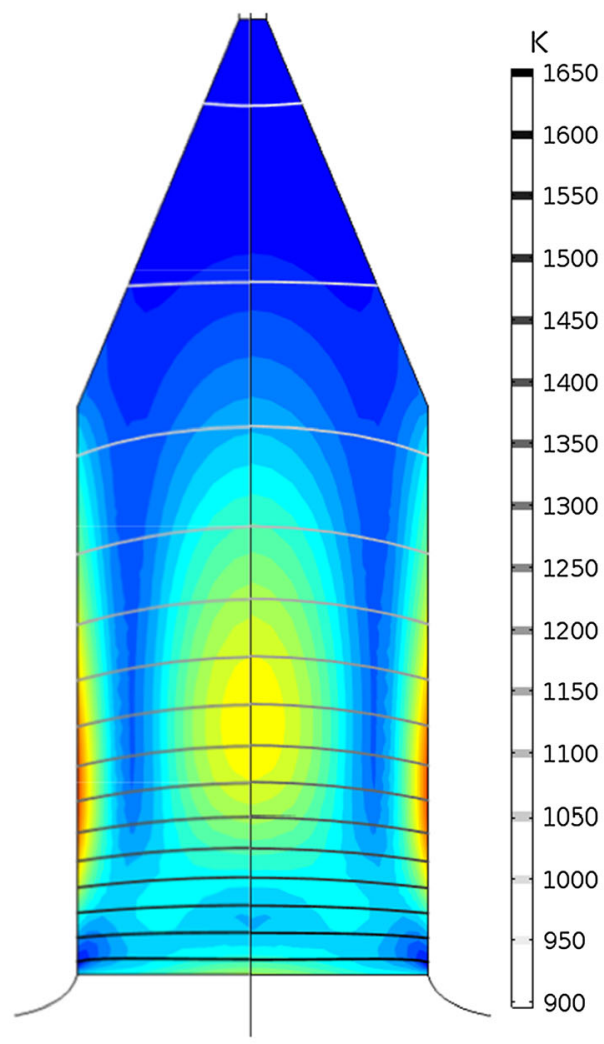

(b)

Fig. 11. Measurement of the crystallization interface shape with LPS (a) and simulation of the temperature and von Mises stress fields in a growing crystal with a diameter of $55 \mathrm{~mm}$ (b).

(see Fig. 9). Such correlations between carrier lifetime and dislocations have also been analyzed in the literature for multi-crystalline silicon. ${ }^{32}$

A correlation between defect distribution and growth conditions such as thermal stresses in the crystal can be expected. The Si-GC process allows for a low crystallization front deflection compared to $\mathrm{FZ}$, as can be observed in the maps obtained by lateral photovoltage scanning (LPS) ${ }^{33}$ based on dopant striations, see Fig. 11a. However, as first numerical simulations demonstrated (Fig. 11b), increased thermal gradients in the crystal may occur due to local heat induction near the crystal surface. Further analysis of thermal conditions and stress distribution will be addressed in a forthcoming paper.

The observed level of carrier lifetime for Si-GC crystals from the growth setup lies in the range from $100 \mu \mathrm{s}$ to $600 \mu \mathrm{s}$ on passivated samples. However, a comprehensive analysis of carrier lifetime limits in silicon in Ref. 31 shows values up to $50 \mathrm{~ms}$ for resistivity below $10 \Omega \mathrm{cm}$ (decreasing to $5 \mathrm{~ms}$ at $1 \Omega \mathrm{cm}$ ). Consequently, there are further carrierlifetime-limiting defects in Si-GC material. Transition metals are known to reduce carrier lifetime in silicon already at concentrations of $10^{11}$
$10^{12} \mathrm{~cm}^{-3}{ }^{34}$ ICP-MS results discussed above showed concentrations up to $10^{14} \mathrm{~cm}^{-3}$ in the crystals; however, a significant fraction of metal contents may be in precipitates and not electrically active. $^{35}$ The electrically active defects were analyzed using a series of further methods:

- Injection-dependent carrier lifetime on passivated samples was also evaluated with a Sinton WCT-120 device using the photoconductance decay (PCD) method. ${ }^{36}$ A good correlation with MPD carrier lifetimes was observed within the uncertainties of each measurement method and sample geometry. A test after dark storage and illumination (conditions: $10 \mathrm{~min}, 0.3$ suns) showed no significant changes in the injectiondependent carrier lifetime.

- Deep-level transient spectroscopy (DLTS) allows us to identify and measure deep-level defects for concentrations 3-4 orders of magnitude below the doping level, i.e., down to $10^{12} \mathrm{~cm}^{-3}$ for the crystal E45 ( $n$-type, $1.5 \Omega \mathrm{cm}$, dopant concentration of $\left.3 \cdot 10^{15} \mathrm{~cm}^{-3}\right)$. First DLTS results using a PhysTech FT1230 device indicate that there are no deep-level defects above this concentration. The main fraction of metallic impurities is probably contained in precipitates, i.e., is not 
electrically active.

The potential for decreased metal contamination in combination with decreased structural defects was demonstrated using the following experiment. A SiGC crystal (similar in quality to E43) was used as a feed rod in an FZ growth process to obtain a dislocation-free crystal where the metals have been segregated once again. ICP-MS measurements in Sec. 3.3 indicated a decrease in the total concentration of transition metals from $3 \cdot 10^{13}-3 \cdot 10^{14} \mathrm{~cm}^{-3}$ in Si-GC crystals to $2 \cdot 10^{13} \mathrm{~cm}^{-3}$ in the FZ crystal. Carrier lifetime measurements of the passivated sample in Fig. 10 show very high values of up to $20 \mathrm{~ms}$, which is expected to be governed by surface passivation. The actual bulk carrier lifetime could not be assessed, but is expected to be even closer to the Auger limit. It should be noted that carrier lifetime may have been influenced not only by changes in metal concentration, but also structural defects. Furthermore, the resistivity was significantly higher in the FZ crystal compared to E45 and E49. Further studies are necessary to determine the exact role of these factors.

\section{CONCLUSIONS}

Silicon crystals grown from melt in a granulate crucible have been characterized with respect to defect contents and material quality. Three crystals with a diameter of $60 \mathrm{~mm}$ and two crystals with a diameter of $15 \mathrm{~mm}$ grown under high-purity conditions were analyzed in detail.

Silicon granulate particles used as feedstock can be described as microscopically porous nanocrystalline material. This structure increases the electrical resistivity of granulate to the level of intrinsic silicon even at low temperatures (reaching $3 \cdot 10^{5} \Omega \mathrm{cm}$ ), which is relevant for inductive melting of granulate. The dopants in granulate are partly compensated and lead to a resistivity of about $150 \Omega \mathrm{cm}$ in crystalline samples. Gas doping with $\mathrm{PH}_{3}$ during crystal growth allows homogeneous resistivity distributions to be achieved, but an adjustment of the dopant inflow and further analysis of the melt flow influence on the radial distribution are necessary.

Impurity analysis of granulate feedstock using ICP-MS revealed relatively high concentrations of transition metals, with the sum of 14 analyzed elements reaching a concentration up to $2 \cdot 10^{15} \mathrm{~cm}^{-3}$. In the grown crystals, this value decreased approximately by one order of magnitude, leading to an average effective segregation coefficient of 0.1 . This value is much higher than the equilibrium coefficients in the range of $10^{-4}-10^{-6}$ and may be caused by undissolved metallic particles in the melt or other currently unclear reasons. FTIR measurements of the crystals showed a low oxygen content, but a significant contamination with carbon originating from the graphite susceptor used during the melting phase of the growth process. This is the most likely source of inclusions ( $\mathrm{SiC}$ ), which we assume behind particles (up to $10 \mu \mathrm{m}$ and higher) observed in infrared transmission or behind scatterers (on nanometer scale) in LST images.

It was demonstrated in a single case that dislocation-free growth is possible from the granulate crucible after successful Dash necking. If dislocations are generated, e.g., by disturbances of the growth interface with small unmolten granulate particles, an unusual distribution with a W-shaped radial profile appears, reaching densities up to $4 \cdot 10^{4} \mathrm{~cm}^{-2}$. This distribution correlates with thermal stresses in the crystal during the growth process, and hence thermal conditions, which should be analyzed in more detail. The presence of a further structural defect in addition to dislocations was indicated by shallow etch pits on longitudinal $\{110\}$ crystal sections. These show a density and distribution comparable to dislocations, but also occur in dislocation-free parts of the crystal. Such shallow pits can be related to voids, inclusions, or other defects and could be identified using transmission electron microscopy in further studies.

Bulk carrier lifetime in n-type crystals grown from the granulate crucible reaches $100 \mu \mathrm{s}$ $(1.5 \Omega \mathrm{cm})$ to $600 \mu \mathrm{s}(14 \Omega \mathrm{cm})$ and demonstrates a good correlation with the dislocation density distribution having a $\mathrm{W}$-shaped radial profile. The carrier lifetime is probably limited by the deep-level defects from various transition metals, but a more exact identification has not yet been performed. If a crystal is purified by metal segregation in an additional FZ growth process, effective carrier lifetimes up to $20 \mathrm{~ms}$ can be reached on passivated samples.

\section{ACKNOWLEDGMENTS}

Open Access funding provided by Projekt DEAL. The authors are indebted to a large number of colleagues for continuous support of this study. The development of the growth process and the realization of growth experiments at the IKZ were performed by B. Faraji-Tajrishi, L. Lehmann, A. Nikiforova, M. Renner, S. Weiß and supported by further members of the Sigret project team. The application of various characterization techniques at the IKZ would have not been possible without S. Bergmann (SEM), C. Guguschev (EDLM), S. Kayser (LPS), A. Kwasniewski (x-ray measurements), T. Markurt (SEM), M. Pietsch (FTIR, resistivity), M. Renner (resistivity), and T. Schulz (LST). We also thank K. Banse, M. Imming-Friedland, V. Lange, and T. Wurche (all IKZ), as well as B. Neubert and A. Albrecht (both TU Freiberg), for sample preparation. ICP-MS analysis was performed by S. Meyer at the Fraunhofer CSP (Halle). We are grateful to Ch. Frank-Rotsch, C. Guguschev, and F.-M. Kießling (all IKZ) for many helpful discussions. This 
work was funded by the Deutsche Forschungsgemeinschaft (DFG, German Research Foundation, Grant 260161677) at the TU Freiberg as well as by the Leibniz Association in the frame of the Leibniz Competition 2016 at the IKZ.

\section{CONFLICT OF INTEREST}

The authors declare that they have no conflict of interest.

\section{OPEN ACCESS}

This article is licensed under a Creative Commons Attribution 4.0 International License, which permits use, sharing, adaptation, distribution and reproduction in any medium or format, as long as you give appropriate credit to the original author(s) and the source, provide a link to the Creative Commons licence, and indicate if changes were made. The images or other third party material in this article are included in the article's Creative Commons licence, unless indicated otherwise in a credit line to the material. If material is not included in the article's Creative Commons licence and your intended use is not permitted by statutory regulation or exceeds the permitted use, you will need to obtain permission directly from the copyright holder. To view a copy of this licence, visit http://creativecom mons.org/licenses/by/4.0/.

\section{REFERENCES}

1. W. von Ammon, Phys. Stat. Sol. A 211, 2461 (2014).

2. R. Menzel, K. Dadzis, N.V. Abrosimov, and H. Riemann, in Proceedings of XVIII International UIE-Congress on Electrotechnologies for Material Processing (2017), pp. 215-220.

3. H. Riemann, N. Abrosimov, M. Renner, and J. Fischer, Patent DE10 2010052522 B4, published 1 June 2011.

4. D.T.J. Hurle and P. Rudolph, J. Cryst. Growth 264, 550 (2004).

5. J. Hofstetter, C.D. Canizo, H. Wagner, S. Castellanos, and T. Buonassisi, Prog. Photovolt. Res. Appl. 24, 122 (2016).

6. C. Roselund, Photovolt. Mag. 9, 88 (2015).

7. P.J. Holmes, Proc. IEE Part B 106, 861 (1959).

8. W. Fulkerson, J.P. Moore, R.K. Williams, R.S. Graves, and D.L. McElroy, Phys. Rev. 167, 765 (1968).

9. N.D. Arora, J.R. Hauser, and D.J. Roulston, IEEE Trans. Electron Dev. 29, 292 (1982).
10. F.M. Smits, Bell Syst. Tech. J. 37, 711 (1958).

11. F. Secco d'Aragona, J. Electrochem. Soc. 119, 948 (1972).

12. E. Sirtl and A. Adler, Zeitschrift für Metallkunde 52, 529 (1961).

13. M. Wright Jenkins, J. Electrochem. Soc. 124, 757 (1977).

14. B.P. Tyagi and K. Sen, Phys. Stat. Sol. A 80, 679 (1983).

15. A. Dennstedt, Diploma thesis, TU Berlin (2004) (in German).

16. W. Zulehner, J. Cryst. Growth 65, 189 (1983).

17. M. Balski, H. Kipphardt, A. Berger, S. Meyer, and U. Panne, Anal. Methods 6, 77 (2014).

18. J. Dietl, Sol. Cells 10, 145 (1983).

19. H.-C. Freiheit, K. Bonauer-Klepp, and R. Baumann, J. Cryst. Growth 304, 317 (2007).

20. T. Buonassisi, A.A. Istratov, M. Heuer, M.A. Marcus, R. Jonczyk, J. Isenberg, B. Lai, Z. Cai, S. Heald, W. Warta, R. Schindler, G. Willeke, and E.R. Weber, J. Appl. Phys. 97, 074901 (2005).

21. D. Macdonald, A. Cuevas, A. Kinomura, Y. Nakano, and L.J. Geerligs, J. Appl. Phys. 97, 033523 (2005).

22. C. Reimann, M. Trempa, J. Friedrich, and G. Müller, J. Cryst. Growth 312, 1510 (2010).

23. M. Naumann and F. Kirscht, Thin Solid Films 487, 188 (2005).

24. W.C. Dash, J. Appl. Phys. 29, 736 (1958).

25. A. Authier and A.R. Lang, J. Appl. Phys. 35, 1956 (1964).

26. Advanced x-ray topography imaging, Annual report of Fraunhofer IISB (2019), pp. 41-43.

27. A.F. Bogenschütz, Ätzpraxis für Halbleiter (Carl Hanser Verlag, München, 1967), pp. 74-75 (in German).

28. T. Abe and T. Takahashi, J. Cryst. Growth 334, 16 (2011).

29. K. Dornich, N. Schüler, B. Berger, and J.R. Niklas, Mater. Sci. Eng., B 6, 676 (2013).

30. G. Dingemans and W.M.M. Kessels, J. Vac. Sci. Technol., A 30, 040802 (2012).

31. A. Richter, S.W. Glunz, F. Werner, J. Schmidt, and A. Cuevas, Phys. Rev. B 86, 165202 (2012).

32. K. Arafune, T. Sasaki, F. Wakabayashi, Y. Terada, Y. Ohshita, and M. Yamaguchi, Phys. B 376-377, 236 (2006).

33. S. Kayser, A. Lüdge, and K. Böttcher, I.O.P. Conf. Ser. Mater. Sci. Eng. 355, 012019 (2018).

34. J.R. Davis, A. Rohatgi, R.H. Hopkins, P.D. Blais, P. RaiChoudhury, J.R. Mccormick, and H.C. Mollenkopf, IEEE Trans. Electron Dev. 27, 677 (1980).

35. A.A. Istratov, T. Buonassisi, R.J. McDonald, A.R. Smith, R. Schindler, J.A. Rand, J.P. Kalejs, and E.R. Weber, J. Appl. Phys. 94, 6552 (2003).

36. J.S. Swirhun, R.A. Sinton, and M.K. Forsyth, Prog. Photovolt. Res. Appl. 19, 313 (2011).

Publisher's Note Springer Nature remains neutral with regard to jurisdictional claims in published maps and institutional affiliations. 